\title{
Ethyl Lauroyl Arginate (LAE): Antimicrobial Activity of LAE-Coated Film for the Packaging of Raw Beef and Pork
}

\author{
Erica Tirloni $\mathbb{D}$, Cristian Bernardi $\mathbb{D}$, and Simone Stella $\mathbb{D}$ \\ Department of Health, Animal Science and Food Safety, University of Milan, Via Celoria 10, IT-20133, Milan, Italy \\ Correspondence should be addressed to Erica Tirloni; erica.tirloni@unimi.it
}

Received 9 November 2020; Revised 17 February 2021; Accepted 13 March 2021; Published 19 March 2021

Academic Editor: Luis Patarata

Copyright (C) 2021 Erica Tirloni et al. This is an open access article distributed under the Creative Commons Attribution License, which permits unrestricted use, distribution, and reproduction in any medium, provided the original work is properly cited.

\begin{abstract}
In this study, the antimicrobial activity of an ethyl lauroyl arginate- (LAE ${ }_{-}$) coated film applied to the packaging of raw beef and pork was evaluated. Two different trials were performed for each meat species, aiming to evaluate the functionality of the film in contrasting the development of the natural microflora and of a specific target agent, Escherichia coli ATCC 25922. In the first trial, LAE-coated packaging was applied to test its activity towards the natural meat microflora over a period of 24 days at $6-7^{\circ} \mathrm{C}$. The comparison with the control sample series showed a slight initial inhibitory activity on total viable count, followed by a growing trend. In the second trial, the antimicrobial activity of the LAE-coated film was evaluated on raw beef and pork voluntarily inoculated with Escherichia coli: an initial killing effect on E. coli was detected in both pork and beef meat (reduction around 0.7 and $1 \log \mathrm{CFU} / \mathrm{g}$, respectively), followed by a stable trend for the following storage period (24 days).
\end{abstract}

\section{Introduction}

Active packaging is a promising method to improve food safety by inhibiting the growth of spoilage and potential pathogenic microorganisms [1]. The incorporation in the packaging of chemoactive and/or bioactive components such as antimicrobial substances may have benefits in terms of extension of food shelf life.

In the last years, ethyl lauroyl arginate (LAE) is receiving particular interest in the field of active packaging for raw meat $[2,3]$. LAE is a surfactant, generally recognized as safe (GRAS) for certain food applications [4] and approved by the Food and Drug Administration (FDA) as a food preservative with concentrations up to $200 \mathrm{ppm}$ [5]; according to the European Union legislation, LAE is approved as a food additive (identified as E243) intended for cooked meat products (with some exceptions) with a maximum concentration of $160 \mathrm{ppm}$ [6]. In fact, LAE is rapidly hydrolysed by the human body through chemical and metabolic pathways and transformed into natural components (lauric acid and L-arginine) [3]. Also, the European Food Safety Authority (EFSA) established an acceptable daily intake
(ADI) of $0.5 \mathrm{mg} / \mathrm{kg} \mathrm{bw}$, taking into account that this compound is possibly present in all food categories [7].

LAE was already proved to possess a strong antimicrobial activity towards a wide range of bacteria including Gram-positive and Gram-negative, yeasts, and molds, resulting in damaging of bacteria membrane with consequent cell inhibition and loss of viability [7-10]. In particular, previous studies showed its ability to reduce up to $3.5 / 4 \log \mathrm{CFU} / \mathrm{mL}$ loads of Listeria monocytogenes, L. innocua, Salmonella enterica, Escherichia coli, E. coli VTEC, and Staphylococcus aureus, among the others [11-14].

As LAE is not volatile, it should be preferably included at direct contact with food to exert its potentiality; some studies reported its use also in combination with other antimicrobial compounds such as cinnamon, eugenol, organic acids, or nisin $[13,15,16]$.

The aim of this study was to evaluate the antimicrobial activity of ethyl lauroyl arginate- $\left(\mathrm{LAE}^{{ }_{-}}{ }_{-}\right.$) coated film, when applied to the packaging process of raw beef and raw pork. Two trials were performed: in the first one, the activity was tested towards the natural meat microflora. The aim of the 
second trial was to evaluate the antimicrobial activity of the LAE-coated film on raw beef and pork voluntarily inoculated with Escherichia coli, used as a target contamination agent.

\section{Materials and Methods}

\subsection{Evaluation of the Antimicrobial Activity of the $L A E^{\circledR}$ - Coated Film on the Microflora of Vacuum-Packaged Raw Beef}

2.1.1. Preparation of Meat Samples. Raw lean beef (rump) was obtained directly from the deboning plant, after slaughtering and a stabilization time at a temperature of 2$3^{\circ} \mathrm{C}$. The beef cuts were sectioned in order to obtain series of $300 \mathrm{~g}$ lean steaks; the total surface of the steaks, in contact with the packaging film, was about $400 \mathrm{~cm}^{2}$; a total of 54 steaks were used at this stage of the study. The meat samples were randomly assigned to one of the two series: reference (R) and LAE-coated. Reference film was a coextruded shrink plastic oxygen barrier material intended to be used for vacuum packaging of fresh proteins. LAE $^{\circledR}$-coated film was obtained by coating reference film with a $\mathrm{LAE}^{\circledR}$ solution obtaining a grammage of around $700 \mathrm{mg} \mathrm{LAE} / \mathrm{sqm}$ of film. The films had thickness $45 \mathrm{um}$, haze $7 \%$, OTR at $23^{\circ} \mathrm{C}$ $100 \mathrm{RH}=17 \mathrm{cc} / \mathrm{sqm}$, and shrink rate at $85^{\circ} \mathrm{C}=40-50 \%$ in both LT and TD (longitudinal and transversal direction). The meat samples were vacuum-packaged (shrinking at $85^{\circ} \mathrm{C}$ for $3 \mathrm{sec}$ ) and stored at $6-7^{\circ} \mathrm{C}$ for the whole duration of the trial.

2.1.2. Sample Analysis. Microbiological analyses were performed in triplicate at Day 0 and at settled times (Day 1, Day 2, Day 3, Day 4, Day 7, Day 10, Day 17, and Day 24). After packaging, the samples intended to be analysed at Day 0 were kept at $2-4^{\circ} \mathrm{C}$ for 3 hours before the analysis, in order to evaluate the initial effect of the packaging material. From each steak, a $25 \mathrm{~g}$ share (taking the surface of the steak by a sterile knife) was taken; after dilution in sterile saline $(\mathrm{Na} /$ tryptone, $0.85 \%$ ), samples were submitted to the evaluation of the following microbiological parameters: TVC (total viable count) by the ISO 4833-2 method [17], count of LAB (lactic acid bacteria), by the ISO 15214 method [18], and enumeration of Enterobacteriaceae by the ISO 21528-2 method [19]. One batch for each experiment was considered.

The results obtained from the two series were logtransformed and compared by statistical analysis (one-way ANOVA) for each sampling time.

\subsection{Evaluation of the Antimicrobial Activity of the $L A E^{\circledR}$ Coated Film on the Microflora of Vacuum-Packaged Raw Pork}

2.2.1. Preparation of Meat Samples. Raw lean pork meat (loin) was taken directly from the slaughterhouse after slaughtering and a stabilization time at a temperature of 2$3^{\circ} \mathrm{C}$. The pork loins were cut in order to obtain series of $200 \mathrm{~g}$ lean steaks; the total surface of the steaks, in contact with the packaging film, was about $300 \mathrm{~cm}^{2}$; a total of 54 steaks were used for the study. The meat samples were randomly assigned to one of the two series: reference $(R)$ and $L_{A E}{ }^{\circledR}$ coated, as described in Section 2.1.1. As for beef, the pork samples were vacuum-packaged (shrinking at $85^{\circ} \mathrm{C}$ for $3 \mathrm{sec}$ ) and stored at $6-7^{\circ} \mathrm{C}$ for the whole duration of the trial.

2.2.2. Sample Analysis. Microbiological analyses were performed in triplicate at Day 0 and at settled times (Day 1, Day 2, Day 3, Day 4, Day 7, Day 10, Day 17, and Day 24) as described above. Microbiological analyses and analysis of the results were performed as described above for beef (Section 2.1.2). One batch for each experiment was considered.

\subsection{Evaluation of the Activity of $L A E^{\circledR}$ on Escherichia coli} Inoculated on Beef Samples during the Shelf Life. Raw lean beef (rump) was taken directly from the slaughterhouse after slaughtering and a stabilization time at a temperature of 2$3^{\circ} \mathrm{C}$. The beef cuts were sectioned in order to obtain series of $300 \mathrm{~g}$ lean steaks; the total surface of the steaks, in contact with the packaging film, was about $400 \mathrm{~cm}^{2}$; a total of 54 steaks were used for the study. The meat samples were randomly assigned to one of the two series: reference and LAE ${ }^{\circledR}$-coated; the characteristics of the materials have been described in Section 2.1.1. One batch for each experiment was considered.

2.3.1. Preparation of E. coli Suspension. E. coli ATCC 25922 strain was used for the tests. The suspension was obtained by an overnight culture of the strain in TSB (Tryptone Soy Broth, Biogenetics, Ponte San Nicolò, Italy) at $37^{\circ} \mathrm{C}$. The bacterial cell concentration was determined by contrast microscopy at 1000x magnification (Motic, B310, Wetzlar, Germany) and adjusted by sterile saline in order to reach a load around $6 \log \mathrm{CFU} / \mathrm{ml}$.

2.3.2. Sample Inoculation and Analyses. All the beef steaks (both sample series) were inoculated on both sides with $0.75 \mathrm{ml}$ of $E$. coli suspension (targeted inoculum concentration of $4 \log \mathrm{CFU} / \mathrm{g}$ ), massaged for one minute, and kept at $2-4^{\circ} \mathrm{C}$ for $30 \mathrm{~min}$ to allow $E$. coli surface attachment. Three samples for each series were vacuum-packaged with the $\mathrm{LAE}^{\circledR}$-coated or the reference packaging material (shrinking at $85^{\circ} \mathrm{C}$ for $3 \mathrm{sec}$ ) and kept at $2-4^{\circ} \mathrm{C}$ for 3 hours; then, the microbiological analyses were performed.

All the remaining beef samples were packaged with the respective film and stored at $6-7^{\circ} \mathrm{C}$ until the end of the trial. Meat samples were analysed in triplicate at Day 0, Day 1, Day 2, Day 3, Day 4, Day 7, Day 10, Day 17, and Day 24. For each sampling time and sample series, three meat packages were aseptically open and the steaks were submitted to the microbiological analyses. From each steak, a $25 \mathrm{~g}$ share (taking the surface of the steak by a sterile knife) was taken; after dilution in sterile saline ( $\mathrm{Na}$ /tryptone, $0.85 \%$ ), the samples were submitted to $E$. coli enumeration according to the ISO 16649-1 method [20].

The results obtained from the two series (LAE ${ }^{\circledR}$-coated and reference) were log-transformed and compared by 
statistical analysis (one-way ANOVA) for each sampling time.

2.4. Evaluation of the Activity of LAE ${ }^{\circledR}$ on Escherichia coli Inoculated on Pork Samples during the Shelf Life. Raw lean pork meat (loin) was taken directly from the slaughterhouse after slaughtering and a stabilization time at a temperature of $2-3^{\circ} \mathrm{C}$. The pork loins were cut in order to obtain series of $200 \mathrm{~g}$ lean steaks; the total surface of the steaks, in contact with the packaging film, was about $300 \mathrm{~cm}^{2}$; a total of 54 steaks were used for the study. All the stages of preparation of $E$. coli suspension, sample inoculation, packaging, storage, and samplings were conducted according to the protocol reported in Section 2.3 and subheadings. One batch for each experiment was considered.

\section{Results}

3.1. Evaluation of the Antimicrobial Activity of the LAE ${ }^{\circledR}$ Coated Film on the Microflora of Vacuum-Packaged Raw Beef and Pork. The results of the trial are shown in Table 1. The initial total viable count of the raw beef samples was within the normal range for fresh beef with optimal hygiene status (around 3-3.5 $\log$ CFU/g). A gradual increase in the counts was observed during the first days of the trial (until Day 4), and then a stabilization occurred, with values constantly around 6-7 log CFU/g, without overcoming the threshold values that are considered as responsible for meat spoilage (7-8 $\log$ CFU/g) [21]. The data showed a slight inhibitory activity by the $\mathrm{LAE}^{\circledR}$-coated material in the samples at Day 0 ( 0.4 log difference); however, the statistical analysis did not reveal any significant difference. The trend of the counts during the trial was the same for the two sample series until Day 4, even if during the last stage of the trial the increase in the counts was higher in $\mathrm{LAE}^{\circledR}$-coated samples. Considering the counts obtained during the whole trial except for the initial sampling $(\Delta \log$ from Day 0$)$, the data analysis revealed the absence of any significant difference. The initial LAB counts were lower than expected for freshly slaughtered beef $(<2 \log \mathrm{CFU} / \mathrm{g})$; a gradual increase of the values was observed, reaching stable counts around $6 \log \mathrm{CFU} / \mathrm{g}$ from Day 17. A significant difference between the two sample series was observed until Day 10 . The analysis of the trend of the counts showed a slower increase until Day 2 in the $\mathrm{LAE}^{\circledR}$-coated series, followed by a faster growth of LAB until Day 7; in the last part of the trial, similar trends were observed. Considering the counts obtained during the whole trial except for the initial samplings, the data analysis revealed the absence of any significant difference between the series from Day 2. The initial Enterobacteriaceae counts were low (below the detection limit of $1.7 \log \mathrm{CFU} / \mathrm{g}$ ), indicating optimal hygiene of the beef used for the trial. The trend of the counts showed a gradual increase from Day 2 that lasted for the whole trial, presumably due to the selection and further development of psychrotrophic Enterobacteriaceae strains, with the counts reaching levels that can be responsible for an initial modification of meat sensory characteristics ( $5 \mathrm{log}$
CFU/g) from Day 10. As expected, a high variability in the counts occurred in the last samplings: such phenomenon is currently observed in the last part of the shelf life of vacuum-packaged raw meat. Considering the whole trial, the trend of the counts showed a lower (also if not significantly) growth rate in $\mathrm{LAE}^{\circledR}$-coated samples until Day 2 ; in the last part of the trial, similar trends were observed. Considering the counts obtained during the whole trial except for the initial sampling, the data analysis revealed the absence of any significant difference between the series.

The initial total viable counts of the raw pork samples were within the normal range for fresh pork meat (about $5 \log \mathrm{CFU} / \mathrm{g}$ ) (Table 2). A decrease in the counts was observed at Day 1, presumably due to postmortem acidification of muscle tissue, coupled with vacuum packaging. Then, the counts detected were stable until Day 4 and gradually increased, as expected, during the further weeks of storage, reaching values that are considered as responsible for meat spoilage (7-8 $\log$ CFU/g) at Day 24. The data showed a slight inhibitory activity by the $\mathrm{LAE}^{\circledR}$-coated material during the first phase of the trial, with a difference of about $0.4 \log$ (Day 0 and Day 1); however, the statistical analysis did not reveal any significant difference. The trend of the counts during the trial was similar for the two sample series, with similar values from Day 2. The differences between the mean values were variable, but in most cases, the TVC obtained from $\mathrm{LAE}^{\circledR}{ }_{-}$ coated samples was higher than the reference ones. Considering the counts obtained during the whole trial except for the initial sampling $(\Delta \log$ from Day 0$)$, the data analysis revealed the absence of any significant difference between the series. The initial LAB counts were low as expected for freshly slaughtered pork meat (1-2 log CFU/g). The trend of the counts was very stable for almost the whole duration of the trial with the absence of detectable counts in most samples $(<1.7 \log \mathrm{CFU} / \mathrm{g})$ and a gradual increase from Day 10 , but with very high variability among the sample units and without reaching high values (always below 6-7 log $\mathrm{CFU} / \mathrm{g}$ ). No detectable differences were revealed between the reference and the $\mathrm{LAE}^{\circledR}$-coated series, due to the presence of very low counts. The analysis of the data obtained at the different sampling times showed the absence of a significant difference between treated and reference sample series. Considering the counts obtained during the whole trial except for the initial sampling, the data analysis revealed the absence of any significant difference between the series. The initial Enterobacteriaceae counts were very low (less than $1.7 \log \mathrm{CFU} / \mathrm{g}$ ), indicating optimal hygiene of the pork meat used for the trial. The trend of the counts was stable until Day 10, thanks to the combination of refrigeration, vacuum packaging, and low initial counts. During the last part of the trial (Days 17 and 24), an evident increase was observed; however, as for beef, the counts did not reach values above $5 \log \mathrm{CFU} / \mathrm{g}$, but high variability in the counts occurred in the last samplings. Due to the very low counts, no inhibitory activity by the packaging with the $\mathrm{LAE}^{\circledR}$-coated material was observed during the first phase of the trial; the analysis of the data obtained at the different sampling times showed the absence of significant difference between treated and reference sample series. 
TABLE 1: Mean TVC, LAB, and Enterobacteriaceae counts obtained in reference and LAE$^{\circledR}{ }^{\circledR}$-coated beef samples during the trial.

\begin{tabular}{|c|c|c|c|c|c|c|c|c|c|}
\hline \multirow[t]{2}{*}{ Series } & \multicolumn{9}{|c|}{$\begin{array}{c}\text { TVC } \\
(\text { Mean }(\log \mathrm{CFU} / \mathrm{g}) \pm s\end{array}$} \\
\hline & Day 0 & Day 1 & Day 2 & Day 3 & Day 4 & Day 7 & Day 10 & Day 17 & Day 24 \\
\hline Reference & $3.51 \pm 0.19$ & $4.00 \pm 0.56$ & $5.25 \pm 0.17$ & $5.84 \pm 0.09$ & $6.45 \pm 0.45$ & $6.55 \pm 0.20$ & $6.64 \pm 0.18$ & $6.69 \pm 0.31$ & $6.63 \pm 0.47$ \\
\hline LAE $^{\circledR}$-coated & $3.12 \pm 0.27$ & $4.00 \pm 0.61$ & $4.82 \pm 0.61$ & $5.21 \pm 0.25$ & $\begin{array}{l}6.25 \pm 0.39 \\
\text { LAB }\end{array}$ & $6.75 \pm 0.03$ & $6.51 \pm 0.17$ & $7.35 \pm 0.09$ & $6.98 \pm 0.21$ \\
\hline \multirow[t]{2}{*}{ Series } & \multicolumn{9}{|c|}{ (Mean $(\log$ CFU/g) \pm st. dev.) } \\
\hline & Day 0 & Day 1 & Day 2 & Day 3 & Day 4 & Day 7 & Day 10 & Day 17 & Day 24 \\
\hline Reference & $1.90 \pm 0.35$ & $2.70 \pm 0.68$ & $3.91^{\mathrm{a}} \pm 0.46$ & $4.39^{\mathrm{a}} \pm 0.16$ & $4.76^{\mathrm{a}} \pm 0.26$ & $5.63^{\mathrm{a}} \pm 0.06$ & $5.62^{\mathrm{a}} \pm 0.22$ & $5.71 \pm 0.33$ & $6.30 \pm 0.63$ \\
\hline LAE $^{\circledR}$-coated & $<1.70$ & $1.86 \pm 0.28$ & $2.36^{\mathrm{b}} \pm 0.59$ & $2.81^{\mathrm{b}} \pm 0.73$ & $3.86^{\mathrm{b}} \pm 0.46$ & $5.12^{\mathrm{b}} \pm 0.25$ & $5.01^{\mathrm{b}} \pm 0.22$ & $5.97 \pm 0.61$ & $5.98 \pm 0.20$ \\
\hline \multirow[t]{2}{*}{ Series } & \multicolumn{9}{|c|}{$\begin{array}{c}\text { Enterobacteriaceae } \\
(\text { Mean }(\log \mathrm{CFU} / \mathrm{g}) \pm \text { st. dev. })\end{array}$} \\
\hline & Day 0 & Day 1 & Day 2 & Day 3 & Day 4 & Day 7 & Day 10 & Day 17 & Day 24 \\
\hline Reference & $<1.70$ & $1.98 \pm 0.49$ & $2.69 \pm 0.60$ & $3.22 \pm 0.31$ & $3.60 \pm 0.43$ & $4.56 \pm 0.81$ & $5.37 \pm 0.20$ & $5.53 \pm 0.25$ & $5.79 \pm 1.04$ \\
\hline LAE $^{\circledR}$-coated & $<1.70$ & $<1.70$ & $1.86 \pm 0.28$ & $2.65 \pm 0.64$ & $3.50 \pm 1.31$ & $5.04 \pm 0.51$ & $4.44 \pm 0.81$ & $6.36 \pm 0.51$ & $6.44 \pm 0.29$ \\
\hline
\end{tabular}

TABLE 2: Mean TVC, LAB, and Enterobacteriaceae counts obtained in reference and $\mathrm{LAE}^{\circledR}$-coated pork samples during the trial.

\begin{tabular}{|c|c|c|c|c|c|c|c|c|c|}
\hline \multirow[t]{2}{*}{ Series } & \multicolumn{9}{|c|}{$\begin{array}{c}\text { TVC } \\
(\text { Mean }(\log \mathrm{CFU} / \mathrm{g}) \pm\end{array}$} \\
\hline & Day 0 & Day 1 & Day 2 & Day 3 & Day 4 & Day 7 & Day 10 & Day 17 & Day 24 \\
\hline Reference & $5.13 \pm 0.17$ & $4.02 \pm 0.27$ & $4.08 \pm 0.43$ & $3.86 \pm 0.28$ & $4.02 \pm 0.37$ & $4.20 \pm 0.48$ & $4.33 \pm 0.33$ & $6.37 \pm 0.37$ & $7.75 \pm 0.26$ \\
\hline \multirow{3}{*}{ Series } & $4.72 \pm 0.24$ & $3.61 \pm 0.20$ & $4.56 \pm 1.15$ & $3.96 \pm 0.24$ & $\begin{array}{l}3.83 \pm 0.30 \\
\text { LAB }\end{array}$ & $4.79 \pm 0.38$ & $4.78 \pm 1.85$ & $6.38 \pm 0.22$ & $8.02 \pm 0.05$ \\
\hline & \multicolumn{9}{|c|}{ (Mean $(\log$ CFU/g) \pm st. dev.) } \\
\hline & Day 0 & Day 1 & Day 2 & Day 3 & Day 4 & Day 7 & Day 10 & Day 17 & Day 24 \\
\hline Reference & $1.96 \pm 0.24$ & $1.86 \pm 0.28$ & $<1.70$ & $1.80 \pm 0.17$ & $<1.70$ & $1.70 \pm 0.00$ & $1.70 \pm 0.00$ & $1.70 \pm 0.00$ & $2.27 \pm 0.99$ \\
\hline LAE $^{\circledR}$-coated & $<1.70$ & $2.00 \pm 0.52$ & $2.00 \pm 0.52$ & $<1.70$ & $<1.70$ & $<1.70$ & $2.25 \pm 0.96$ & $2.76 \pm 1.83$ & $3.83 \pm 1.86$ \\
\hline \multirow[t]{2}{*}{ Series } & \multicolumn{9}{|c|}{$\begin{array}{c}\text { Enterobacteriaceae } \\
(\text { Mean }(\log \text { CFU/g) } \pm \text { st. dev. })\end{array}$} \\
\hline & Day 0 & Day 1 & Day 2 & Day 3 & Day 4 & Day 7 & Day 10 & Day 17 & Day 24 \\
\hline Reference & $<1.70$ & $<1.70$ & $<1.70$ & $<1.70$ & $<1.70$ & $<1.70$ & $<1.70$ & $2.70 \pm 1.73$ & $3.70 \pm 0.88$ \\
\hline LAE $^{\circledR}$-coated & $<1.70$ & $<1.70$ & $<1.70$ & $2.06 \pm 0.62$ & $<1.70$ & $<1.70$ & $2.19 \pm 0.85$ & $4.82 \pm 0.10$ & $4.15 \pm 1.26$ \\
\hline
\end{tabular}

3.2. Evaluation of the Activity of $L A E^{\circledR}$ on Escherichia coli Inoculated on Beef and Pork Samples during the Shelf Life. The data obtained at Day 0 (day of meat samples packaging) showed the presence of an evident inhibitory activity on Escherichia coli by the application of a $\mathrm{LAE}^{\circledR}$-coated packaging material in beef samples (Table 3). A statistically significant difference $(P<0.01)$ was observed between the two series, with LAE-coated samples showing values lower of about 0.7 log when compared to the reference ones (Table 3 ). During the rest of the trial, thanks to the storage and packaging conditions, no significant growth was observed in both series. From Day 1, no further inactivation effect of the $\mathrm{LAE}^{\circledR}{ }^{\circledR}$-coated material was observed, as the E. coli counts showed only slight variations, and the same trend was observed for the treated and reference samples until the end of the trial, without a significant residual bactericidal activity. Considering the whole trial duration, except for the initial sampling ( $\Delta \log$ from Day 0$)$ and the differences among the samplings, the data analysis revealed the absence of any significant difference between the series.

Also considering the pork samples (Table 4), the data obtained at Day 0 (day of meat samples packaging) showed the presence of an inhibitory activity on $E$. coli by the application of the $\mathrm{LAE}^{\circledR}$-coated packaging material: a statistically significant difference $(P<0.01)$ between the two series was detected, with $\mathrm{LAE}^{\circledR}$-coated samples showing values lower of about $1.0 \mathrm{log}$ when compared to the reference ones. During the rest of the trial, thanks to the storage and packaging conditions, no significant growth was observed in both series. From Day 1, no further inactivation effect of the $\mathrm{LAE}^{\circledR}$-coated material was observed, as the $E$. coli counts showed only slight variations, and the same trend was observed for the two series resulting in a constant difference between treated and reference samples until the end of the trial, without a significant residual bactericidal activity. As for beef, considering the counts obtained during the whole trial except for the initial sampling, the data analysis revealed the absence of any significant difference between the series.

\section{Discussion}

The antimicrobial activity of LAE towards various microorganisms has been widely described, and its application to food packaging is being evaluated by several authors. Its efficacy has been demonstrated against the main foodborne pathogens such as Listeria, Salmonella, E. coli, and 
TABLE 3: Mean E. coli counts obtained in reference and LAE$^{\circledR}$-coated beef samples during the trial.

\begin{tabular}{|c|c|c|c|c|c|c|c|c|c|}
\hline \multirow{2}{*}{ Series } & \multicolumn{9}{|c|}{ Mean $(\log \mathrm{CFU} / \mathrm{g}) \pm$ st. dev. } \\
\hline & Day 0 & Day 1 & Day 2 & Day 3 & Day 4 & Day 7 & Day 10 & Day 17 & Day 24 \\
\hline Reference & $3.98^{\mathrm{A}} \pm 0.02$ & $3.67^{\mathrm{a}} \pm 0.10$ & $3.77^{\mathrm{A}} \pm 0.03$ & $3.92^{\mathrm{A}} \pm 0.02$ & $3.61 \pm 0.09$ & $3.59 \pm 0.26$ & $3.60^{\mathrm{A}} \pm 0.09$ & $3.70^{\mathrm{A}} \pm 0.02$ & $3.66 \pm 0.21$ \\
\hline $\mathrm{LAE}^{\circledR}$-coated & $3.28^{\mathrm{B}} \pm 0.10$ & $3.29^{\mathrm{b}} \pm 0.20$ & $2.69^{\mathrm{B}} \pm 0.26$ & $3.52^{\mathrm{B}} \pm 0.06$ & $3.36 \pm 0.19$ & $3.04 \pm 0.28$ & $3.22^{\mathrm{B}} \pm 0.07$ & $2.91^{\mathrm{B}} \pm 0.17$ & $2.70 \pm 0.61$ \\
\hline $\begin{array}{l}\text { Difference }\left(\mathrm{LAE}^{\circledR}\right. \\
\text { coated - - ref.) }\end{array}$ & -0.70 & -0.38 & -1.08 & -0.40 & -0.25 & -0.55 & -0.38 & -0.79 & -0.96 \\
\hline
\end{tabular}

TABLE 4: Mean E. coli counts obtained in reference and LAE$^{\circledR}$-coated pork samples during the trial.

\begin{tabular}{|c|c|c|c|c|c|c|c|c|c|}
\hline \multirow{2}{*}{ Series } & \multicolumn{9}{|c|}{ Mean $(\log C F U / g) \pm$ st. dev. } \\
\hline & Day 0 & Day 1 & Day 2 & Day 3 & Day 4 & Day 7 & Day 10 & Day 17 & Day 24 \\
\hline Reference & $4.08 \pm 0.20$ & $3.96 \pm 0.05$ & $4.01 \pm 0.04$ & $3.84 \pm 0.20$ & $4.21 \pm 0.10$ & $4.03 \pm 0.05$ & $4.04 \pm 0.28$ & $3.94 \pm 0.23$ & $3.74 \pm 0.08$ \\
\hline LAE $^{\circledR}$-coated & $3.29 \pm 0.16$ & $3.36 \pm 0.19$ & $3.32 \pm 0.28$ & $3.28 \pm 0.24$ & $3.40 \pm 0.25$ & $3.44 \pm 0.24$ & $3.20 \pm 0.34$ & $2.98 \pm 0.36$ & $3.22 \pm 0.38$ \\
\hline $\begin{array}{l}\text { Difference } \\
\text { (LAE }{ }^{\circledR} \text {-coated - -ref.) }\end{array}$ & -0.79 & -0.60 & -0.69 & -0.56 & -0.81 & -0.59 & -0.84 & -0.96 & -0.52 \\
\hline
\end{tabular}

Campylobacter, showing a wide range of activity (including both Gram-positive and Gram-negative bacteria), while some spoilage agents such as Pseudomonas spp. showed a higher resistance [11].

Most studies faced the contamination of cooked meat products by Listeria spp. and Salmonella spp., showing a good efficacy of the treatment, as adjunct to both the foodstuff and the packaging film $[8,16,22-24]$. A good efficacy was also evidenced on Campylobacter spp. and Salmonella spp. that contaminate raw poultry meat $[25,26]$. Moore et al. [27] found that LAE treatments on poultry meat resulted in reductions in Salmonella counts of $0.9 \mathrm{log} \mathrm{CFU} / \mathrm{g}$ and reductions in Campylobacter jejuni counts of $1 \log \mathrm{CFU} /$ $\mathrm{g}$ when compared to control series. Also, Bechstein et al. [28] reported that $1,500 \mathrm{ppm}$ LAE in minced meat resulted in a significant reduction of the $C$. jejuni concentrations directly after treatment (Day 1) and on Day 7 when compared to the untreated control samples, while treatment of whole breast meat with 400 and 1,000 ppm LAE resulted in significantly lower C. jejuni concentrations when compared to control samples.

The efficacy of LAE on E. coli was evidenced in broth and in milk $[2,13,15]$, while scarce data are available on its activity on the surface of foodstuffs. Anyway, it has to be noted that the action of LAE on a complex matrix like meat is expected to be lower when compared to broth, due to its fast degradation by different pathways [3]. The results obtained in this study indicate the presence of an initial killing effect of $E$. coli inoculated in beef and pork (with an average difference of $0.7-1 \log$ CFU/g). This effect was evidenced just at the first sampling, after three hours of contact with the packaging film: this fast activity has been previously described and is favoured by the rapid release of LAE in an aqueous environment like the surface of raw meat [3]. Afterwards, the trend of the counts of the two sample series was very similar, indicating a rapid loss of activity of $\mathrm{LAE}^{{ }^{\circledR}}$ coated packaging film against the target microorganism and the absence of a residual antimicrobial activity during the shelf life of vacuum-packaged beef and pork. Such behaviour was observed by previous studies, showing the efficacy of LAE in causing an initial inactivation of different pathogens, followed by a recovery and subsequent growth during storage of meat and poultry products (reviewed by Ma et al. [29]). Such action could be explained by the mechanism of action of LAE, as some studies observed damage of the cell membranes caused by LAE, but without cell lysis, thus allowing, in some cases, the possibility for the microorganisms to recover $[13,30]$. Moreover, it has to be considered that the activity of LAE is associated with the positive charge carried by this molecule that could be gradually contrasted by the presence of anionic components on the meat surfaces [29,31]. For a continuative antimicrobial activity during meat storage, a combination with other molecules with different activity has been suggested $[16,32]$.

Considering the effect of LAE-coated film on the natural microflora of raw beef and pork, a very slight inhibitory activity was detected at the beginning of the trial, with a difference in TVC values of 0.3-0.4 log CFU/g; also for $\mathrm{LAB}$ and Enterobacteriaceae, a slight difference was observed. Then, no further inhibitory activity was demonstrated for any of the microbial parameters considered. The lower efficacy towards the natural microflora was expected: in fact, all the microbial groups considered are composed of different genera and species, with different metabolic activity and ability to overcome the hurdle represented by the presence of LAE. This is of particular concern for raw meat that is characterized by a rich and variable microflora coming from animal, human, or environmental sources during the production phases. Literature data show an unclear effect of LAE on the natural microflora: the authors in $[25,26]$ did not report an inhibitory effect by LAE against total mesophilic counts in raw chicken breast fillets (some effect was observed on psychrotrophic counts), although it was effective on inoculated Salmonella spp. and Campylobacter jejuni. An inhibitory effect was instead reported by Higueras et al. [33] on mesophilic and psychrotrophic 
bacteria and on coliform counts on the same meat typology, while no available data could be found concerning raw beef or pork.

In the light of the possible use of LAE as an antimicrobial hurdle for the storage of vacuum-packaged raw meat, the application of a coated packaging film seems a promising approach, as it acts directly on the surface of meat pieces, where the microbial contamination occurs. The interest of food producers in the potential application of LAE as a food additive is confirmed by the requests for an enlargement of foodstuffs where its use can be allowed [34]. The potential activity of LAE on both Gram-positive and Gram-negative bacteria [29] makes this molecule particularly interesting for the use of complex matrices; nevertheless, the richness and variety of the microbial population of raw meat require a specific research and evaluation activity, aiming to supply new hurdles to be combined and to assure a sufficient microbiological quality of raw meat during the whole shelf life.

\section{Data Availability}

The data used to support the findings of this study are available from the corresponding author upon request (erica.tirloni@unimi.i).

\section{Conflicts of Interest}

The authors declare no conflicts of interest.

\section{Authors' Contributions}

E. T. and S. S. conceptualized the study, performed formal analysis and data curation, investigated the data, and prepared the original draft; E. T., C. B., and S. S. were responsible for methodology; S. S. reviewed and edited the manuscript and supervised the study and was involved in project administration. All authors have read and agreed to the published version of the manuscript.

\section{References}

[1] V. Muriel-Galet, J. P. Cerisuelo, G. López-Carballo, S. Aucejo, R. Gavara, and P. Hernández-Muñoz, "Evaluation of EVOHcoated PP films with oregano essential oil and citral to improve the shelf-life of packaged salad," Food Control, vol. 30, no. 1, pp. 137-143, 2013.

[2] M. Kashiri, J. P. Cerisuelo, I. Domínguez, G. López-Carballo, P. Hernández-Muñoz, and R. Gavara, "Novel antimicrobial zein film for controlled release of lauroyl arginate (LAE)," Food Hydrocolloids, vol. 61, pp. 547-554, 2016.

[3] C. Nerin, R. Becerril, S. Manso, and F. Silva, "Ethyl lauroyl arginate (LAE): antimicrobial activity and applications in food systems," in Antimicrobial Food Packaging, J. Barros-Velazquez, Ed., Academic Press, Cambridge, UK, pp. 305-312, 2016.

[4] D. Asker, J. Weiss, and D. J. McClements, "Analysis of the interactions of a cationic surfactant (lauric arginate) with an anionic biopolymer (pectin): isothermal titration calorimetry, light scattering, and microelectrophoresis," Langmuir, vol. 25, no. 1, pp. 116-122, 2009.
[5] G. Bakal and A. Diaz, "The lowdown on lauric arginate: food antimicrobial hammers away at plasma membrane, disrupting a pathogen's metabolic process," Food Quality, vol. 12, no. 1, pp. 54-61, 2005.

[6] European Union, "Regulation (EC) No 1333/2008, of the European parliament and of the council of 16 December 2008 on food additives," Official Journal of the European Union, vol. 354, p. 3112, 2008.

[7] European Food Safety Authority (EFSA), "Opinion of the scientific panel on food additives, flavourings, processing aids and materials in contact with food on a request from the commission related to an application on the use of ethyl lauroyl arginate as a food additive-question number EFSAQ-2006-035," European Food Safety Authority Journal, vol. 5, no. 7, p. 511, 2007.

[8] J. B. Luchansky, J. E. Call, B. Hristova, L. Rumery, L. Yoder, and A. Oser, "Viability of listeria monocytogenes on commercially-prepared hams surface treated with acidic calcium sulfate and lauric arginate and stored at $4^{\circ} \mathrm{C}$," Meat Science, vol. 71, no. 1, pp. 92-99, 2005.

[9] E. Rodriguez, J. Segeur, X. Rocabayera, and A. Manresa, "Cellular effects of monohydrochloride of l-arginine, nalpha-lauroyl ethylester (LAE) on exposure to Salmonella typhimurium and Staphylococcus aureus," Journal of Applied Microbiology, vol. 96, no. 5, pp. 903-912, 2004.

[10] S. A. Ruckman, X. Rocabayera, J. F. Borzelleca, and C. B. Sandusky, "Toxicological and metabolic investigations of the safety of N- $\alpha$-Lauroyl-l-arginine ethyl ester monohydrochloride (LAE)," Food and Chemical Toxicology, vol. 42, no. 2, pp. 245-259, 2004.

[11] R. Becerril, S. Manso, C. Nerin, and R. Gómez-Lus, “Antimicrobial activity of lauroyl arginate ethyl (LAE), against selected food-borne bacteria," Food Control, vol. 32, no. 2, pp. 404-408, 2013.

[12] V. Muriel-Galet, J. P. Cerisuelo, G. López-Carballo, M. Lara, R. Gavara, and P. Hernández-Muñoz, "Development of antimicrobial films for microbiological control of packaged salad," International Journal of Food Microbiology, vol. 157, no. 2, pp. 195-201, 2012.

[13] R. Pattanayaiying, A. H-Kittikun, and C. N. Cutter, "Effect of lauric arginate, nisin $\mathrm{z}$, and a combination against several food-related bacteria," International Journal of Food Microbiology, vol. 188, pp. 135-146, 2014.

[14] K. A. Soni, R. Nannapaneni, M. W. Schilling, and V. Jackson, "Bactericidal activity of lauric arginate in milk and queso fresco cheese against listeria monocytogenes cold growth," Journal of Dairy Science, vol. 93, no. 10, pp. 4518-4525, 2010.

[15] Q. Ma, P. M. Davidson, and Q. Zhong, "Antimicrobial properties of lauric arginate alone or in combination with essential oils in tryptic soy broth and $2 \%$ reduced fat milk," International Journal of Food Microbiology, vol. 166, no. 1, pp. 77-84, 2013.

[16] E. M. Martin, C. L. Griffis, K. L. S. Vaughn et al., "Control of listeria monocytogenes by lauric arginate on frankfurters formulated with or without lactate/diacetate," Journal of Food Science, vol. 74, no. 6, pp. M237-M241, 2009.

[17] International Organization for Standardization (ISO), Microbiology of the Food Chain-Horizontal Method for the Enumeration of Microorganisms-Part 2: Colony Count at 30 Degrees by the Surface Plating Technique. ISO 4833-2:2013, International Organization for Standardization, Geneva, Switzerland, 2013.

[18] International Organization for Standardization (ISO), Microbiology of Food and Animal Feeding Stuffs-Horizontal 
Method for the Enumeration of Mesophilic Lactic Acid Bacteria-Colony-Count Technique at 30 Degrees. ISO 15214:1998, International Organization for Standardization, Geneva, Switzerland, 1998.

[19] International Organization for Standardization (ISO), Microbiology of Food and Animal Feeding Stuffs-Horizontal Methods for the Detection and Enumeration of Enterobacteriaceae-Part 2: Colony-count Method. ISO 21528-2: 2017, International Organization for Standardization, Geneva, Switzerland, 2017.

[20] International Organization for Standardization (ISO), Microbiology of the Food Chain-Horizontal Method for the Enumeration of Beta-Glucuronidase-Positive Escherichia coli-Part 1: Colony-count Technique at 44 Degrees C Using Membranes and 5-Bromo-4-Chloro-3-Indolyl Beta-DGlucuronide. ISO 16649-1:2018, International Organization for Standardization, Geneva, Switzerland, 2018.

[21] A. I. Doulgeraki, D. Ercolini, F. Villani, and G.-J. E. Nychas, "Spoilage microbiota associated to the storage of raw meat in different conditions," International Journal of Food Microbiology, vol. 157, no. 2, pp. 130-141, 2012.

[22] M. Guo, T. Z. Jin, L. Wang, O. J. Scullen, and C. H. Sommers, "Antimicrobial films and coatings for inactivation of listeria innocua on ready-to-eat deli Turkey meat," Food Control, vol. 40, pp. 64-70, 2014.

[23] P. J. Taormina and W. J. Dorsa, "Inactivation of listeria monocytogenes on hams shortly after vacuum packaging by spray application of lauric arginate," Journal of Food Protection, vol. 72, no. 12, pp. 2517-2523, 2009.

[24] P. Theinsathid, W. Visessanguan, J. Kruenate, Y. Kingcha, and S. Keeratipibul, "Antimicrobial activity of lauric arginatecoated polylactic acid films against listeria monocytogenes and Salmonella typhimurium on cooked sliced ham," Journal of Food Science, vol. 77, no. 2, pp. 142-149, 2012.

[25] D. V. T. Nair, R. Nannapaneni, A. Kiess, B. Mahmoud, and C. S. Sharma, "Antimicrobial efficacy of lauric arginate against campylobacter jejuni and spoilage organisms on chicken breast fillets," Poultry Science, vol. 93, no. 10, pp. 2636-2640, 2014.

[26] C. S. Sharma, A. Ates, P. Joseph, R. Nannapaneni, and A. Kiess, "Reduction of salmonella in skinless chicken breast fillets by lauric arginate surface application," Poultry Science, vol. 92, no. 5, pp. 1419-1424, 2013.

[27] A. Moore, R. Nannapaneni, A. Kiess, and C. S. Sharma, "Evaluation of USDA approved antimicrobials on the reduction of salmonella and campylobacter in ground chicken frames and their effect on meat quality," Poultry Science, vol. 96, no. 7, pp. 2385-2392, 2017.

[28] D.-V. Bechstein, J. Popp, N. Sudhaus-Joern, and C. Krischek, "Effect of ethyl-lauroyl-arginate hypochloride in combination with high hydrostatic pressure processing on the microbial load and physico-chemical characteristics of minced and portioned chicken breast meat," Poultry Science, vol. 98, no. 2, pp. 966-976, 2019.

[29] Q. Ma, P. M. Davidson, and Q. Zhong, "Properties and potential food applications of lauric arginate as a cationic antimicrobial," International Journal of Food Microbiology, vol. 315, p. 108417, 2020.

[30] J. Coronel-León, A. López, M. J. Espuny et al., “Assessment of antimicrobial activity of $\mathrm{N} \alpha$-lauroyl arginate ethylester (LAE) against yersinia enterocolitica and lactobacillus plantarum by flow cytometry and transmission electron microscopy," Food Control, vol. 63, pp. 1-10, 2016.

[31] P. U. Singare and J. D. Mhatre, "Cationic surfactants from arginine: synthesis and physicochemical properties,"
Journal of the American Chemical Society, vol. 2, pp. 186190, 2012.

[32] A. C. S. Porto-Fett, S. G. Campano, J. L. Smith et al., "Control of Listeria monocytogenes on commercially-produced frankfurters prepared with and without potassium lactate and sodium diacetate and surface treated with lauric arginate using the sprayed lethality in container (SLIC) delivery method," Meat Science, vol. 85, no. 2, pp. 312-318, 2010.

[33] L. Higueras, G. López-Carballo, P. Hernández-Muñoz, R. Gavara, and M. Rollini, "Development of a novel antimicrobialfilm based on chitosan with LAE (ethyl-N $\alpha$ dodecanoyl-L-arginate) and its aplication to fresh chicken," International Journal of Food Microbiology, vol. 165, no. 3, pp. 339-345, 2013.

[34] European Food Safety Authority-Panel on Food Additives and Flavourings (EFSA), "Scientific opinion on the safety of ethyl lauroyl arginate (E 243) as a food additive in the light of the new information provided and the proposed extension of use," European Food Safety Authority Journal, vol. 17, no. 3, p. 5621, 2019. 